\title{
The treatment technique of dynamic analysis of highway slope diseases under complicated geological conditions of high temperature and rainy area
}

\author{
Haiping $\mathrm{Li}^{1,2, a}$, Rongxiang Shani $\mathrm{i}^{1,2, \mathrm{~b}}$ \\ ${ }^{1}$ China Merchants Chongqing Communications Research \& Design Institute Co., \\ Ltd.,Chongqing 400067; ${ }^{2}$ National Engineering \& Research Center for Highways in Mountain \\ Area, Chongqing 400067; \\ a2739254930@qq.com b29051618@qq.com
}

Keyword : slope disease, cataclastic rock mass, deformation stage, dynamic treatment technology

Abstract: Under abnormal climatic conditions, a large number of cutting slope deformation instability problems that plagued expressway operation have become one of the major security issues. The formation lithology, geological structure and other inner factors are closely related to the stability problem of expressway cutting slope during the process of occurring and development, and the meteorological, hydrology and earthquake and other external conditions are also major predisposing factor of slope deformation and development. Based on the Guanghe expressway K66 + 250 K66 + 534 on the right slope engineering geological environment, the process of deformation and deformation history of the different stages of research, think that the cataclastic rock mass slope failure slip having an arcuate surface at the macro Features, and at the micro exhibits along the slope failure modes have jointed, level of development jagged or stepped features. In addition, this paper also puts forward a specific proposal for the prevention and treatment of the type of expressway slope diseases.

Construction of expressway is gradually extending to mountainous ares featured by such complicated geological conditions that high and steep slopes are formed along it. Under complicated geology, landforms and geological hydrology, many types of troubles concerned slopes come into being in service and the damages caused by deformations of cutting slope have become one of the most serious security issues that beset the expressway service. Based on a close relationship between occurrence and deterioration of deformation on cutting slope and the inner factors such as features of rock in stratum, the geological structure and so on so forth,some extrinsic factors like metrology, hydrology and construction become the main incentives $(1,2)$ causing deformations and deterioration of cutting slope. Under a complicated geological condition in rainy and hot area, deformation of slopes formed by broken rocks become one of the common geological hazards in the period of expressway service in hilly areas.

This paper, exemplified by the treatment of right slope on section K66+250 K66+534 in Gangue Expressway, made a detailed analysis of destructive mechanism caused by deformation of slopes formed by broken rocks Under a complicated geological condition in rainy and hot area, and proposed in particular a reasonable suggestion for treating slope hazards, which provided experience that can be learnt to employ in the prevention and treatment of the similar type of slope hazard in similar areas.

\section{A general survey of slope and geological conditions of project}

A general survey of slope

The right slope on section K66+250 K66+534 in Gangue Expressway is in the height of $31 \mathrm{~m}$. The original design employed a method of protection by hanging spray seeding after grading slope. 
The first hazard appeared during the construction in June, 2010. Afterwards anchor frame beam is used to reinforce the Grade-I and Grade III of slope, and anchor cable frame beam is taken to consolidate Grade II of slope. But from June and July in 2011, deformation of some sections is worsening in the period of implementing reinforcement. Crosshead anchor gridiron beam is added to reinforce Grade I. In June, 2012, with the top of the slope cracking and the surface of slope and pavement bulging, rock and soil mass as a whole structure showed a sign of integral slide and loss of stability.

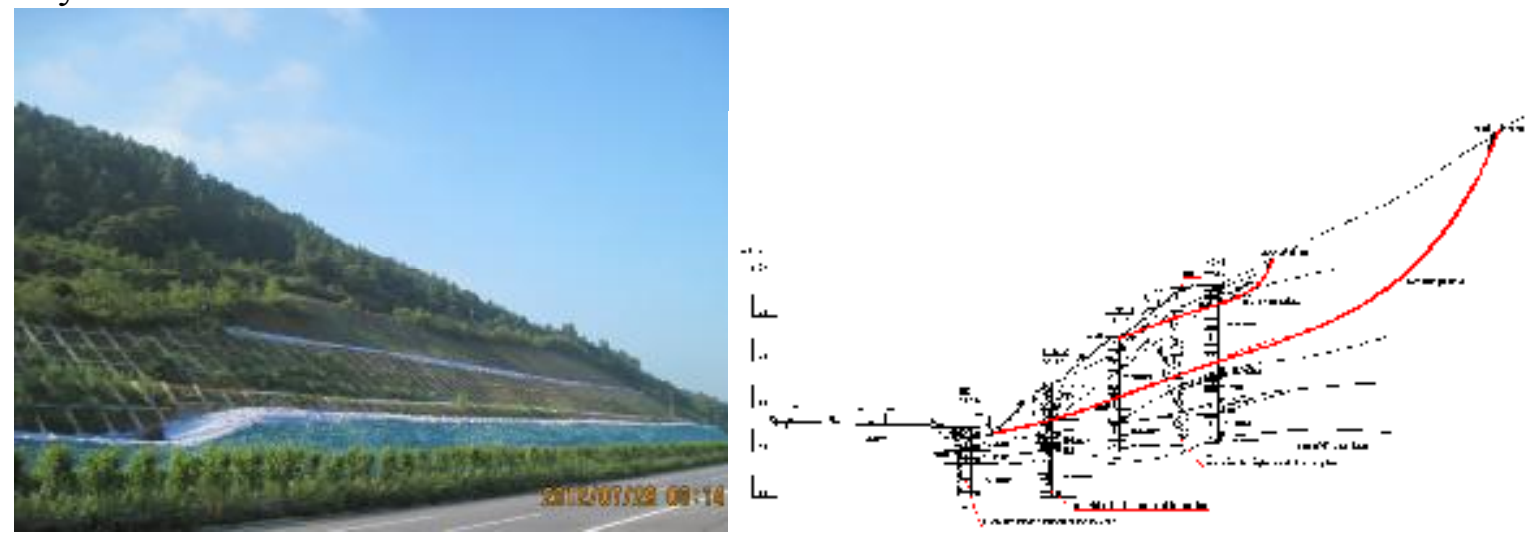

Fig. 1 emergency treatment and deformation of slope Fig. 2 typical geological section of slope The geological conditions of slope project

The slope is seated in the tropical area, southern Asia, with a yearly average temperature of $21.6{ }^{\circ} \mathrm{C}$ and the lowest temperature of $12.1{ }^{\circ} \mathrm{C}$. It has a lot of rains with a yearly average rainfall of $1960 \mathrm{~mm}$ in this area. From April to September is rain season and from October to next March is dry season. The typhoon and stormy rain had an impact on the expressway in service.

The geomorphology in the field is shallow hilly geomorphology. The elevation of the present land is about $24.47 \mathrm{~m} \sim 123.5 \mathrm{~m}$, with a gap of $99.03 \mathrm{~m}$ compared to the previous. The natural slope gentle inclined, with a ratio of $15 \sim 25^{\circ}$. However, the geology in the back with the deformed cracks in the rear is steep, with a ratio of $30 \sim 35^{\circ}$.

The composition of rocks in the slope is colluvial loam, broken stones and Upper Devonian argillaceous siltstone, argillaceous siltstone, fine sandstone, sandstone, weathered layer made of shale featured with argillaceous siltstone and limestone. There are many types of rocks and an obvious different degree of weathering with a great change in the thickness of weathered layers. The slope is almost completely weathered - highly weathered rock. The top is covered with colluvial sand clay with big change of thickness and broken rocks. under the roadbed on the foot of the slope lies limestone, presenting an unconformable contact with the land covering on the top.

Within the area of the slope, groundwater is mainly classified into Overburden groundwater and water from the crack of bedrock. The ground water is chiefly supplemented by rainfall and discharged by the way of lateral runoff to the valley outside the slope.

\section{An analysis of mechanism of deformation in slope}

The structural features of materials in slope

The upper slope is mainly made of residual sand clay with a big change of thickness, uneven distribution and loos structure. The lower is completely weathered and highly weathered sand rocks the structure of which is rather broken, dense crack with interval of $5 \mathrm{~cm} \sim 20 \mathrm{~cm}$ and intercalated mud, of is fully developed, attitude of is greatly fluctuated, due to the formation, so it is hard to spot a stable layer. The lowest part is an uncomfortable contact with gently 
weathered and little weathered limestone, seated in the broken and massive shapes, whose surface is uneven and sharply changed. $(3,4)$

Construction of slope and the process and characteristics of deformation

Slope was under construction in 2009, and the evacuation was almost finished by May, in 2010. The ratio of Grade I slope was 1:1, and Grade II and III is $1: 1.25$, with a graded height of $10 \mathrm{~m}$ and platform width of $2.0 \mathrm{~m}$. In the rain season of June, 2010, penetrating crack can be seen in a minimile end of Grade II and III slope an top with a width of $10 \mathrm{~cm}$. Top and platform of Grade II showed a sign of sliding downward. The ditch of Grade I platform is deformed and surface is bulged outward. The preventive and protective plan is adjusted to that, anchor grillage beam is employed in Grade I slope, anchor cable frame beam in Grade II, and anchor grillage beam in the seriously suffered section in Grade III. In this phase, the main characteristics of deformation in slope is that the cracks in the rear are located with the area influenced by evacuation of slope, and the bulged section in the front is seated in the middle-lower section of Grade I slope with a deformation in shallow-middle part and potential sliding surface in the depth influenced by the evacuation, whose destructive features carry a characteristics in an obvious similar soil slope hazard.

By June, 2011, the construction of slope reinforcement developed into Grade I slope, but owing to a constant stormy rain, the original hazard of this slope was worsened. With a lot of penetrating rain exuding from the surface of Grade I and II slope, Grade I collapsed with a serious effusion and a severely deformed bulge in ditch; the original cracks in Grade II and III were deformed further with a width of $5-9 \mathrm{~cm}$ from the outer area of top to the top itself. On the basis of strengthening supervision, we made a strengthened preventive and protective plan. 3 lines of prestressed anchor cable frame beam is set in the collapsed section in Grade I (crosshead beam was applied previously), and inclined upward drainage holes were paved to reinforce the work of blocking and drain aging in depth. The deformation in this phase is an intensification and development based on the last phase, and the depth of deformation went into the deeper part and the rear. Meanwhile, influenced by the scour an immersion of intensive rainfall, some parts of loose soil on the surface of slope were sliding and collapsing.

At the beginning of 2012, a second-time treatment of reinforcement was complicated. In June of a strong rainy season, 2012, a lot of centralized rainfall penetrated into the slope, which led to a hazard of sliding in the slope with a total sliding volume of $40 \times 104 \mathrm{~m} 3$.. There was a crack caused by tensioning the outer side of the slope top with a dislocation height of I'm. The old deformed cracks was widened with a bulged and collapsing surface in Grade I, and the whole structure of lattice beam dislocated and cracked with many cracks on the surface of slope and platform of Grade I and II falling. the side ditch was overthrown, and the sub-grade of driving ways was bulged upwards, but obvious deformation was not seen in the slope of Grade III. Some parts of slope in Grade II were bulged, but the whole structure was integral. In a word, partial parts were damaged, but most of the integrity was not bad. The whole slope had a fast deformation. The explicit features of this deformation are as follows: the depth and thickness of deformation were greatly increased, and the rear of the deformation extended to the back. At the same time, due to the impact of deformation, in the some sections of Grade I slope, soil was loose and structure was destroyed, which performed a sign of sliding and collapsing wider the condition of rainy scour and immersion.

In July of 2012, the management department organized the constructers to conduct a reverse press on Grade I slope, and crack pouring on the slope, which controlled the speed of deformation in the slope for a while.

\section{Analysis of deformation mechanism and influencing factors}

The main ingredients of the slope is highly completely weathered sandstones, so influenced by 
the composition of the rocks and weathering, the the cracks in the rocks were densely developed, and very broken, belonging to the category of broken rocks. In accordance to the construction of slope and process of deformation, the deformation can be divided into two stages: stage one is concerned with slope, which mainly covered the influenced area by evacuation of slope or was called as slope evacuation unloading loose area—-stage of deformation of slope; stage two is formation of sliding surface in depth, in which the whole of the slope was sliding and became unstable. A respective introduction to these two stages are as follows:

Phase I - deformation of slope

According to the above analysis, before conducting a treatment of reinforcing the slope, the stability of the slope was influenced by the geographic forms, composition and rainfalls. Based on the condition that the broken rocks composed the slope, from a macroscopic view, the features of deformation carry a destructive characteristics of similar soil slope deformation the potential sliding face of slope damage is in a shape of arc, and at the same time, controlled by the Joint fissures of structure and layers, from a microscopic view, sliding surface will follow the Joint fissures and layers - the microscopic sliding surface performs the features of serrated and step shape. All in all, the damaged area caused by deformation of slope was located in where the evacuation was influenced, which is characterized by that the tensioned cracks caused by deformation are mainly located in the surface of the slope and the area nearby the signalized line of the slope, and shear exit was located on the foot of the slope and Grade I.

Founded on the above analysis, on the basis of the theory of limiting equilibrium,numerical simulation was employed to make an analysis of the deformation and the tendency of it before taking a preventive and protective method to treat the deformation. The results are as followed.

on the basis of the theory of limiting equilibrium, the results of analyzing the tendency of deformation in slope are following in Fig. 3
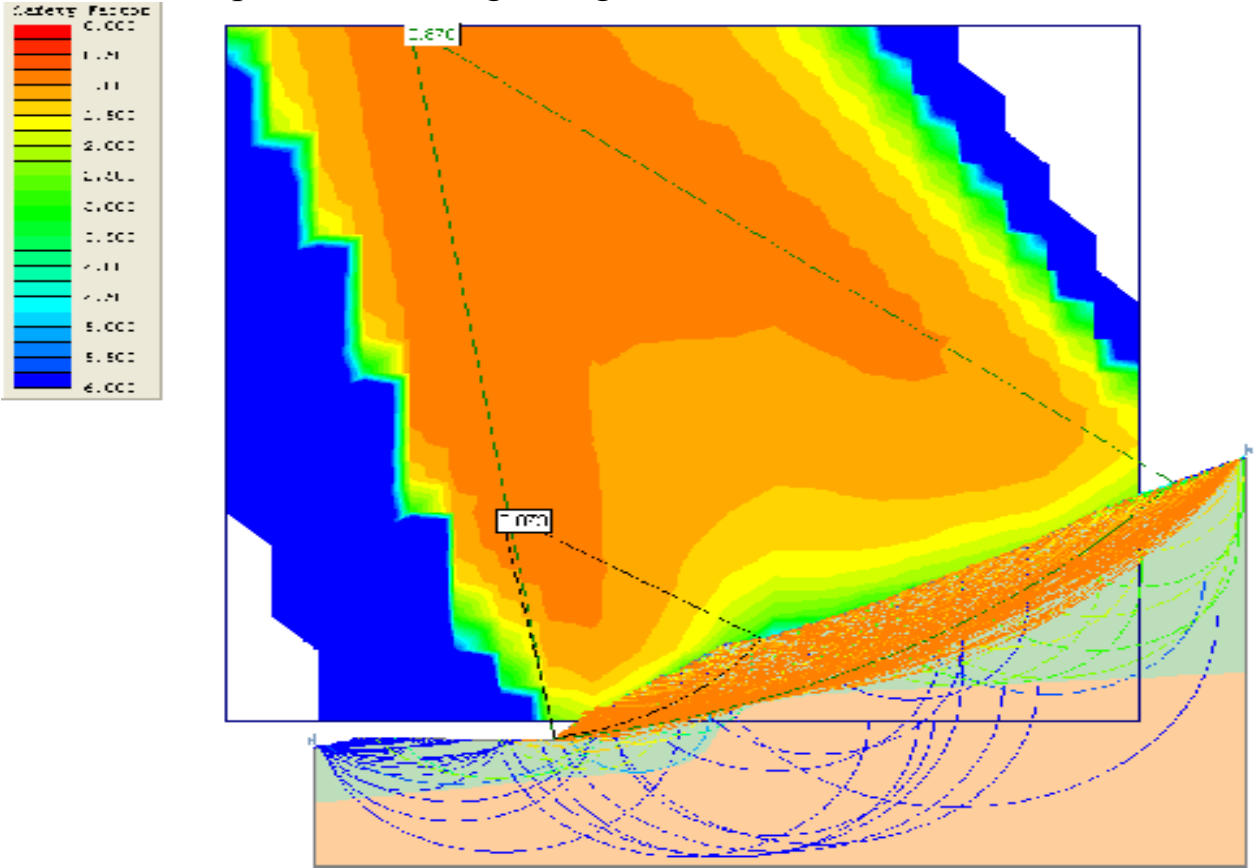

Fig. 3 the trend of slope deformation before consolidation $(\mathrm{K} 66+380)$

The results of numerical simulation of deformation in the slope are following in Fig. 4 andFig. 5 


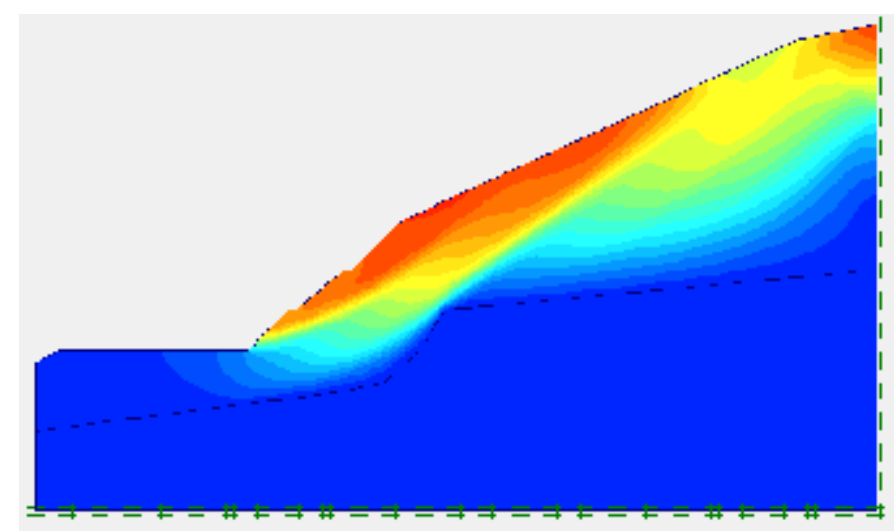

Fig. 4 deformation cloud image of the section excavation without support $(\mathrm{K} 66+380)$

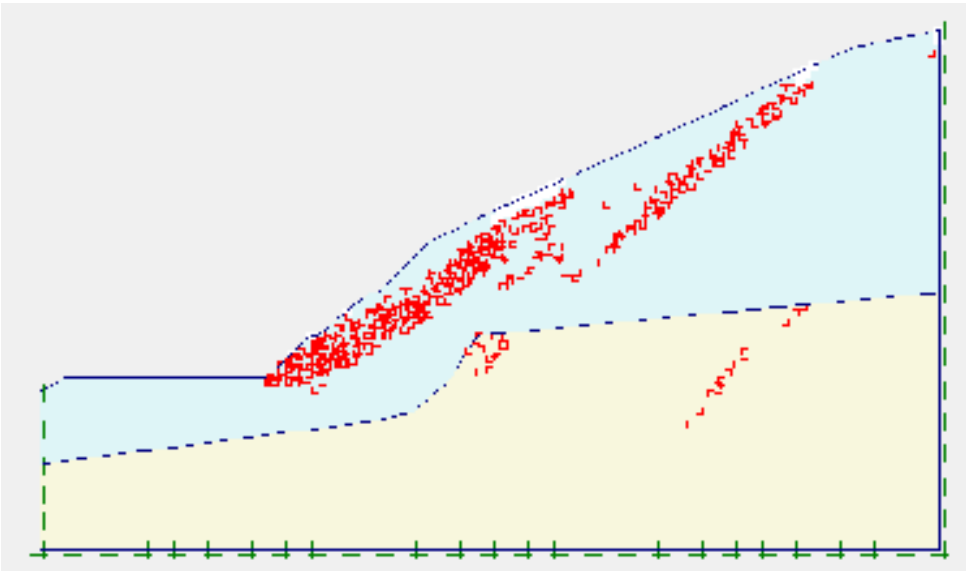

Fig. 5 Distribution diagram of the plastic zone of the excavation without support $(\mathrm{K} 66+380)$

We made a numerical simulation of the evacuated unsupported slope,from the grid and nephogram, we can see that evacuated slope deformed in a shape of retrogression. Because of an unstable slope, a run-through sliding surface came into being in the shallow part of slope. In the upper part, there appeared tensile stress area, and the secondary deep sliding surface was in the formation.

Stage Two_ _ the deep sliding surface was formed, and the whole slope lost stability

Besides the influencing factors in stage one, there are some unique characters of deformation of the slope in this stage. The details are as followed:

After conducting a treatment of reinforcing the slope, on the basis that the deformation of the slope was controlled by the above factors in stage one, because of the constraint of such a treatment, it is inevitable the deformation extended to the depth and the rear and new sliding surface was formed beyond the function of the treatment or the weak part of it. The depth of the slope was hard rocks-limestone, whose top had an effective constraint of the tendency that the rocks of the slope extended to the depth, because the formation of the sliding surface in the depth of the slope was also controlled by the top of the limestones. Under above conditions, the deep sliding surface developed into the following characteristics: the potential sliding face of slope damage is in a shape of arc, and at the same time, controlled by the Joint fissures of structure and layers, from a microscopic view, sliding surface will follow the Joint fissures and layers--the microscopic sliding surface performs the features of serrated and step shape. At the same time, restricted by the conducted treatment of reinforcement, a new sliding surface would be formed beyond the function of the treatment or the weak part of it. Under the condition that the middle-lower part of the slope was influenced by the top of the limestone, the new sliding surface will develop along the uncomfortable contact zone. And the corresponding features of deformation is that there are tension 
cracks and dislocation in the remote rear, and the foot of the slope and pavement in the front of slope were bulged. Actually an abnormality exposed by the geophysical exploration is a direct explanation of weak plane after the formation of the sliding surface.

The results of numerical simulation of deformation in the slope are following in Fig. 6 and Fig.7:

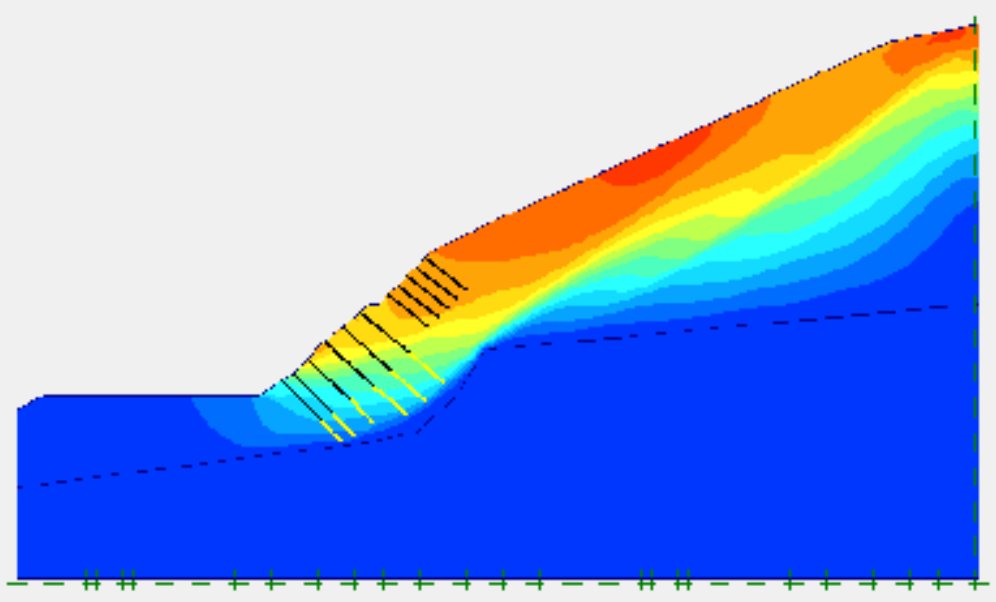

Fig.6 deformation cloud image of the section excavation after second support

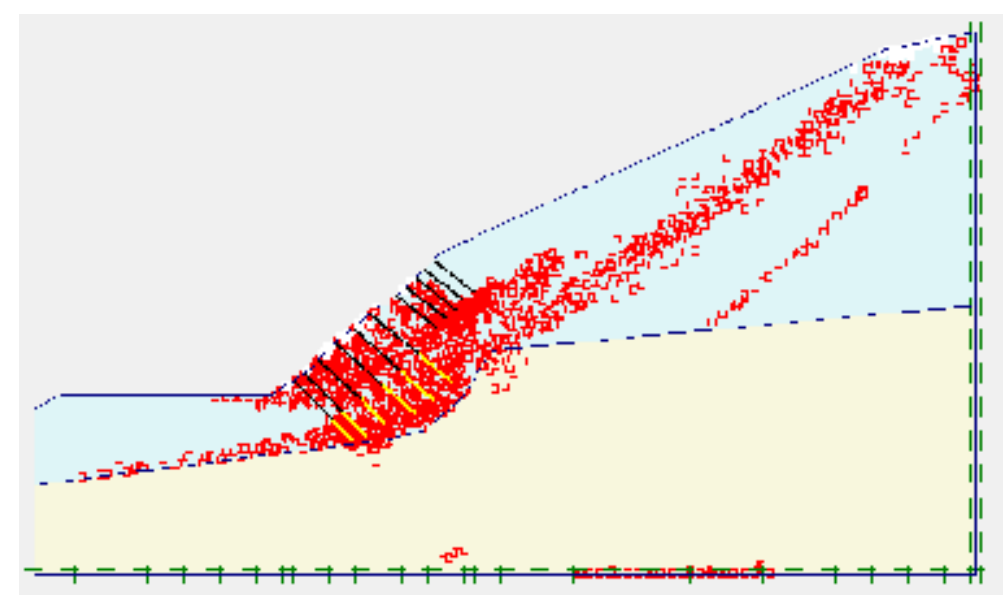

Fig.7 Distribution diagram of the plastic zone of the excavation after second support

We made a numerical simulation of the evacuated unsupported slope, from the grid and nephogram, after we support the slope, the deformation developed upwards, which can seen form that the sliding surface limited by the supportive structure extended to the depth and a new deep sliding surface was formed. From a plastic distribution, we see that after the old sliding surface, a deep run-through sliding one was formed, which is outside the supported area and led to an ineffectiveness, and continuous deformation. Those are all evidence, like bulge of sub-grade, of partial slope and tension cracks in the upper part.

Analysis of stability

The steep stairs, sliding stairs and cracks in the back wall of the sliding slope were newly formed, and the trees nearby were inclined or fell dow. the deformation of the slope also had a tendency to further develop. In present phase, crack pouring to seal the cracks was employed. After we took method of revers press on the foot of Grade I, the speed of deformation was controlled for a while, but the observation data showed that the indicator of of slope deformation data hadn't completely converged, and the slope was in condition from instability to under stability

The treatment of reinforcement in the shallow and middle part of slope was conducted, and 
much of it didn't perform a massive ineffectiveness, except for only in the partial part, which was caused by that the local rocks were sliding and collapsing because of rainy scour. Therefore, we take that into consideration the whole deep slope was sliding and losing stability when calculating slope stability.

According to the present condition of the slope, taking a method of arc sliding to make a simulation, and of polygonal sliding line mixing with the exploration data, we made an Inversion of the process of deformation. By making a simulation of the deformation, we can analyse its tendency of deformation.

Table 1 Table of calculation results of stability coefficient of landslide before back pressure

\begin{tabular}{c|c|c|c|c}
\hline Cross section & Calculating results & $\begin{array}{c}\text { Present } \\
\text { condition }\end{array}$ & Stormy rain & addition \\
\hline K66+380 & Deep Sliding & 0.92 & 0.90 & instability \\
\hline K66+420 & Deep Sliding & 0.97 & 0.93 & nstability \\
\hline
\end{tabular}

Table 2 Table of calculation results of stability coefficient of landslide after back pressure

\begin{tabular}{c|c|c|c|c}
\hline Cross section & Calculating results & Present condition & Stormy rain & addition \\
\hline K66+380 & Deep Sliding & 1.00 & 0.96 & weak-instability \\
\hline K66+420 & Deep Sliding & 1.05 & 1.01 & weak \\
\hline
\end{tabular}

Table 3 Calculated results of residual sliding force (Deep slip surface)

\begin{tabular}{c|c|c|c|c}
\hline Cross section & $\begin{array}{c}\text { condition of } \\
\text { construction }\end{array}$ & $\begin{array}{c}\text { indicator of } \\
\text { stability }\end{array}$ & $\begin{array}{c}\text { Residual } \\
\text { thrustT(Kn) } \\
\mathrm{Fs}=1.20\end{array}$ & $\begin{array}{c}\text { Residual } \\
\text { thrustT(Kn) } \\
\text { Fs=1.15 }\end{array}$ \\
\hline \multirow{2}{*}{ K66+380 } & natural & 0.92 & 2638.08 & 2433.12 \\
\cline { 2 - 5 } K66+420 & stormy rain & 0.90 & & \\
\cline { 2 - 5 } & natural & 0.97 & 2668.20 & 2678.79 \\
\hline
\end{tabular}

3.2 A comprehensive analysis

According to the evaluation of macro-stability and calculating results of stability above, Before the revers press was taken, the whole slope was sliding and the stability was in so poor a condition that the slope deformed at a fast speed. After the revers press was taken, the deformation of the slope was brought under control to some extent and the stability was improved, but it was also situated between instability and weak stability.

\section{Analysis of the technique of treating hazard slope}

In accordance to the analysis above, the deformation of slope is a dynamic process. With the exposure time lengthening, the process of support in construction changing, the area, depth and mode of deformation are also in a constant development an change. In present phase, on one hand, 
rocks in shallow and middle part were sliding. On the other hand, the rocks as a whole in the deep part are sliding, too. Influenced by the sliding of rocks and soil, on the surface of the slope the loose soil in some parts are sliding and collapsing, so the plan of treatment should center on the above problems. The remaining slope after the deformation of the evacuation went forward to the sliding in depth, and the thrust was big. Because the common retaining wall and anchoring don't work well, it is better to take anti-slide pile as . Since many treatments of reinforcement were conducted, the deformation in this phase hadn't damaged the previous support, which had a constraint of the deformation in the shallow-middle section of the slope and can be used. As for the the sliding on the surface of the slope, afforestation could be employed to protect the slope besides a reinforcement of anchor. During the continuous rainfall, there were much ground water exuding from the Grade I slope and the foot of it. The measures of strengthening the drainage in the deep slope and restoring such a drainage in different grades are to be taken.

Plan of acute treatment design

To avoid that the deformation continued to evolve towards the rear, we should guarantee, before measures of reinforcement of anchoring is taken, the stability of the whole part of the slope, improve the exterior environment and control the speed of deformation, to create the conditions under which we can conduct the treatment. Ditch of reinforced concrete with variable cross sections is to be built in a $20 \mathrm{~m}$-distance from crack in the rear, which has a good tensile results, making use of that at foot of slope lies in the rescue path with $8 \mathrm{~m}$-height of reverse press, $8 \mathrm{~m}$-width of top of platform, and t1:1.25 ratio of slope.

Because we take measures of reverse press in time, according to the results and analysis monitored, slope is stable and reverse press works well, which wins time to strengthen the slope.

Plan of dealing with the hazard of slope

According to the condition of slope and calculating results, we should make support construction, drainage construction and some other measures integrated to completely solve the problems and don't leave any dangers. To maintain the present ratio of the slope, we deal with the hazard of the slope. A comprehensive treatment follow the idea of taking pile as the main measure supplemented by anchor. The plan is anchor cable anti-slide pile + prestressed anchor cable frame.

Anti-slide pile as the main support is to be paved on the platform of Grade I. According to the different strengths thrust, the cross section adopts $1.8 \mathrm{~m} \times 2.6 \mathrm{~m} 、 2 \mathrm{~m} \times 3 \mathrm{~m} 、 2.2 \mathrm{~m} \times 3.4 \mathrm{~m}$ with interval of $6.0 \mathrm{~m}$. 2 3 hole anchor cable is to be paved on the top of the pile, with drilling diameter of $\Phi 150 \mathrm{~mm}$, length of $38 \mathrm{~m}, 42 \mathrm{~m}$, and inclination of $26^{\circ}$ and $28^{\circ}$. Each hole owns 7 steel strands with the section of anchoring of $10 \mathrm{~m}$, designed tension of $800 \mathrm{KN}$ and locked tension of $800 \mathrm{KN}$.

Anchor cable ground beam is to be paved on the Grade II, whose section of anchoring lies beneath the deep sliding surface (gently weathered layer). Drilling diameter is $\Phi 150 \mathrm{~mm}$, length $45 \mathrm{~m}$, and inclination $20^{\circ}$. Each hole owns 4 steel strands with the section of anchoring of $10 \mathrm{~m}$, designed tension of $450 \mathrm{KN}$ and locked tension of $500 \mathrm{KN}$.

Anchor cable frame beam is to be paved on Grade III, with the $20.0 \mathrm{~m}$ length of anchor cable. Drilling diameter is $\Phi 150 \mathrm{~mm}$, and inclination $20^{\circ}$. Each hole owns 4 steel strands with the section of anchoring of $10 \mathrm{~m}$, designed tension of $350 \mathrm{KN}$ and locked tension of $400 \mathrm{KN}$.

Drainage: In rainy season, the ground water in the slope is much. The design employs the inclined hole through the deep sliding surface to drain the water. The surface of slope and cracks of the platform are sealed with mortar, and cracks in the top of cut are sealed by clay.The ditches of different grade are cleaned and smoothed. The drainage system is connected and improved. 


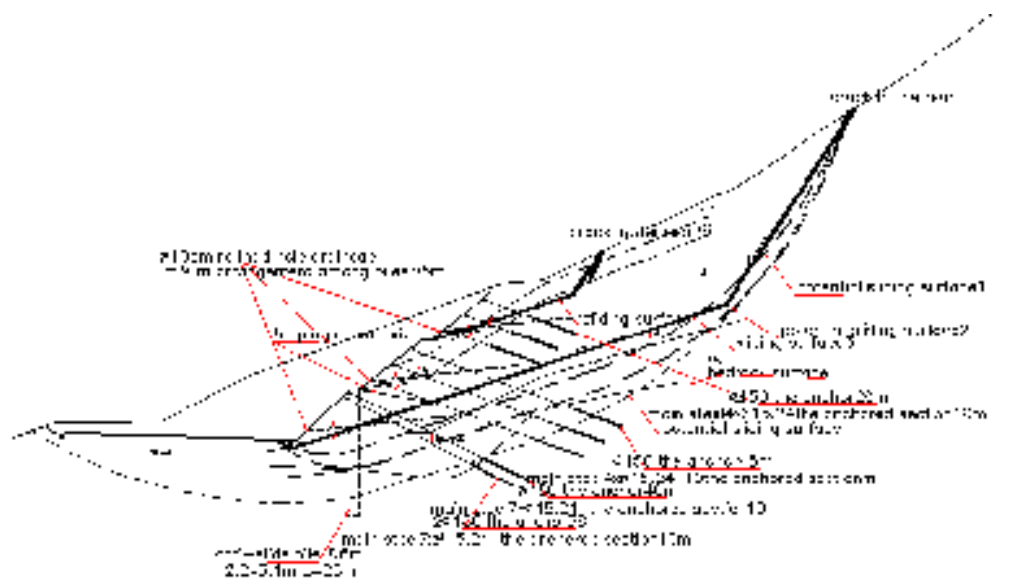

Fig. 8 design of slope reinforcement section $(\mathrm{K} 6+420)$

\section{Conclusion}

The right slope on section K66+250 K66+534 in Gangue Expressway is a mixed slope controlled by many different factors, lying in a hot and rainy area with a complicated geology. Based on the a detailed analysis of deformation mechanism and influencing factors, the paper proposes that the damaged sliding surface of broken rocks is arc form a macro view, and cracks develop along joints from a micro view. The development of the layer is destroyed in a shape of crenation and stairs. The deformation of the slope is characterize with progressiveness and develops stage by stage. On the basis of these features, the treatment of reinforcement of slope adopts the method of controlling the detrimental factors, considering the minor factors, and taking anti-slid pile as the main support and anchor as the supplement. Drainage is assisted to improve the inner environment and a comprehensive treatment of many measures combined is adopted. In dealing with the slope, a design is realized well by keeping the whole part stable and construction an service safe.

The development of hazard of slope is a dynamic communication, and the cognition of the formative mechanism is also a process deepened step by step. So it is crucial to succeed in treating the hazard by strengthen ing the control of different phase, making an immediate adjust with the change of exterior conditions (like weather, the adjustment of deformation phase), and then chasing timing to reinforce,

\section{Acknowledgements}

This work was financially supported by the National Technology Supporting Plan Program: A Control of Disaster of Subgrade and Dynamic Regulate and Control Technology in Southwestern Mountain Areas (2015BAK09B01)

\section{References}

[1] Chen Zuyu. Analysis of Slope Steadiness (Principles, Methods, Procedures). Bejing: Water Resources and Electric Power, 2004

[2] Guangdong Highway Reconnaissance and Planning Designing Institute. A Constructive Geology Prospecting Report of Comprehensive TreatmentRight Sliding Slope of Guanghe Highway Combing and Overpass K66+250 K66+580 [R]. Guangzhou, 2012.

[3]-----. A Constructive Disign of Comprehensive TreatmentRight Sliding Slope of Guanghe Highway Combing and Overpass K66+250 K66+580 [R]. Guangzhou, 2012. 
[4]Zhang Zhuoyuan, Wang Shitian, Wang Lansheng. The Principles of Analyzing Constructive Geology. Beijing: Geology Press, 1981.

[5] Xiao Shufang, Yang Shubi. Rocks Mechanics. Beijing: Geology Press, 1987. 